\title{
Propofol suppresses proliferation and invasion of glioma cells by upregulating microRNA-218 expression
}

\author{
JINQUAN XU, WEIYUN XU and JIAQUN ZHU \\ Department of Anesthesiology, Jinhua Municipal Central Hospital, Jinhua, Zhejiang 321000, P.R. China
}

Received February 27, 2014; Accepted November 19, 2014

DOI: $10.3892 / \mathrm{mmr} .2015 .4014$

\begin{abstract}
Propofol (2,6-diisopropylphenol) is a commonly used intravenous anesthetic agent. The present study aimed to assess the effect of propofol on the proliferation and invasion of human glioma cells, and to determine the potential underlying molecular mechanisms. The effects of propofol on U373 glioblastoma cell proliferation, apoptosis and invasion were detected by an MTT assay, caspase-3 activity measurement and a Matrigel $^{\mathrm{TM}}$ invasion assay, respectively. MicroRNA (miR)-218 expression and matrix metalloproteinase (MMP)-2 protein expression levels were analyzed by quantitative polymerase chain reaction and western blot analysis, respectively. In addition, miR-218 precursor was transfected into the cells to assess whether overexpression of miR-218 could affect MMP-2 expression. Anti-miR-218 was transfected into the cells to evaluate the role of miR-218 in the effects of propofol on the biological behavior of glioma cells. The results of the present study demonstrated that propofol significantly increased the expression levels of miR-218, inhibited U373 cell proliferation and invasion, and facilitated apoptosis. In addition, treatment with propofol efficiently reduced MMP-2 protein expression levels, and overexpression of miR-218 also decreased MMP-2 protein expression levels. Whereas, neutralization of miR-218 using the anti-miR-218 antibody reversed the effects of propofol on the biological behavior of U373 cells, and on the inhibition of MMP-2 protein expression. In conclusion, propofol may effectively suppress proliferation and invasion, and induce the apoptosis of glioma cells, at least partially through upregulation of miR-218 expression.
\end{abstract}

\section{Introduction}

Glioma arises from glial cells and represents the most prevalent diagnostic category of primary brain tumor in the adult

Correspondence to: Dr Weiyun Xu, Department of Anesthesiology, Jinhua Municipal Central Hospital, 351 Mingyue Street, Jinhua, Zhejiang 321000, P.R. China

E-mail: weiyunxudr@163.com

Key words: propofol, matrix metalloproteinase-2, microRNA-218, glioma, proliferation, invasion population (1). According to the World Health Organization (WHO) classification, which is based on histomorphological criteria, human gliomas are divided into well-differentiated low grade astrocytomas (WHO grades I-II), anaplastic astrocytomas (AA, WHO grade III) and glioblastoma (GBM, WHO grade IV). Regardless of recent significant improvements in therapeutic technologies, such as neurosurgery, radiotherapy, chemotherapy and photodynamic therapy, the median survival time for patients with GBM is only 12-15 months, and 2-5 years for patients with anaplastic glioma $(2,3)$. One of the predominant reasons for the low survival rates is that the active cell migration and invasion of GBM cells ultimately leads to ubiquitous tumor recurrence and patient mortality (4). Previous studies have identified numerous molecules that are involved in glioma tumorigenesis and progression (5). Among these molecules, matrix metalloproteinases (MMPs) have been shown to have an important role, due to their ability to degrade extracellular matrix proteins (6). It has previously been reported that the expression levels of MMP-2 are increased in human glioma and this increase is associated with advanced histopathological grade, cell growth and apoptosis, tumor invasion and metastasis, and radiotherapeutic sensitivity (7).

MicroRNAs (miRNAs) are a class of naturally occurring, small (21-25 nucleotides), noncoding RNAs. They bind through partial sequence homology to the 3'-untranslated region of target mRNAs, and may either block translation or promote mRNA degradation (8). As well as their involvement in diverse biological processes, including cell growth, apoptosis, development, differentiation and endocrine homeostasis (8), emerging evidence has suggested that the deregulation or dysfunction of miRNAs may contribute to human carcinogenesis and cancer progression (9). Aberrant expression of miRNAs or mutations in miRNA genes have been well characterized in human glioma $(10,11)$. miR-218 has been identified as being downregulated in numerous types of human malignancy (12-14). Furthermore, Xia et al (15) and Zhang et al (16) identified the repressive role of miR-218 in glioma as it was shown to inhibit cell growth and invasion, and induce cell apoptosis.

Propofol (2,6-diisopropylphenol) is a commonly used intravenous anesthetic agent, which has gained wide acceptance since its introduction in the late 1980s (17). As well as its numerous anesthetic advantages, propofol exerts certain non-anesthetic effects. Previous studies have identified its tumor-suppressive functions in various types of cancer (18-21). Thus suggesting that propofol may be a better agent, as 
compared with other anesthetics, for use in cancer surgery (22). However, the potential antitumor effects of propofol in glioma remain unknown. The present study aimed to determine the influence of propofol on the biological behavior of GBM cells, and the role of miR-218 in these effects.

\section{Materials and methods}

Cell culture and reagents. The U373 human GBM cell line was obtained from the Shanghai Institute of Cell Biology, Chinese Academy of Sciences (Shanghai, China). The cells were cultured in Dulbecco's modified Eagle's medium (DMEM; Invitrogen Life Technologies, Carlsbad, CA, USA) supplemented with $10 \%$ fetal bovine serum (FBS; Sigma-Aldrich, St. Louis, MO, USA), 2 mM glutamine (Qiagen, Shanghai, China), $100 \mathrm{U} / \mathrm{m}$ penicillin (Qiagen) and $100 \mathrm{mg} / \mathrm{ml}$ streptomycin (Qiagen) at $37^{\circ} \mathrm{C}$ in an atmosphere containing $5 \% \mathrm{CO}_{2}$. Propofol was purchased from Sigma-Aldrich and dissolved in dimethyl sulfoxide (DMSO; Sigma-Aldrich) for in vitro analysis. An MMP-2 ELISA kit was obtained from R\&D Systems Europe, Ltd. (Abingdon, UK). $\beta$-actin (1:300, sc-130656) and MMP-2 (1:2,000, sc-10736) polyclonal rabbit antibodies were supplied from Santa Cruz Biotechnology, Inc. (Dallas, TX, USA). The U373 cells were treated with control or different concentrations of propofol $(1,5,10 \mu \mathrm{g} / \mathrm{ml})$ in this study.

Cell viability assay. Cell viability was measured in 96-well plates using a quantitative colorimetric MTT assay (Sigma-Aldrich). Briefly, at the indicated times after treatment with propofol, $20 \mu \mathrm{l}$ MTT $(5 \mathrm{mg} / \mathrm{ml})$ was added to each corresponding well and incubated at $37^{\circ} \mathrm{C}$ for $4 \mathrm{~h}$ in a humidified incubator. The MTT solution was then removed and $200 \mu \mathrm{l}$ DMSO was added to each well for $15 \mathrm{~min}$, in order to dissolve the colored formazan crystals. The absorbance of each aliquot was measured at a wavelength of $570 \mathrm{~nm}$ using a multidetection microplate reader (BMG LABTECH, Cary, NC, USA). The experiments were independently repeated three times and the results represent the mean \pm standard deviation (SD).

Apoptosis assay by Hoechst 33258 staining and caspase-3 activity measurement. Nuclear morphology was analyzed using a confocal laser scanning microscope (IX51; Olympus Corporation, Tokyo, Japan) following staining of the U373 GBM cells with Hoechst 33258 (Sigma-Aldrich). Control and propofol-treated U373 cells were washed in ice cold phosphate-buffered saline (Qiagen) and stained with Hoechst 33258 for $5 \mathrm{~min}$. The cells were mounted on poly L-lysine coated slides (Qiagen), and dead cells and apoptotic bodies were determined as those with condensed or fragmented nuclei as observed using a LSM 5 Live microscope (Carl Zeiss, Shanghai, China). In order to further detect apoptosis at the molecular level, the activity of caspase-3, a key enzyme in the regulation of apoptotic cascades, was also measured using a caspase colorimetric protease assay. Briefly, the cells were cultured in 96-well plates and treated with various concentrations of propofol, prior to being assayed using a Caspase 3 Colorimetric Assay kit (Promega Corporation, Madison, WI, USA), according to the manufacturer's instructions.
Matrigel $^{T M}$ invasion assay. Invasion assays were performed in triplicate using a 24-well invasion chamber system coated with Matrigel $^{\mathrm{TM}}$ (50 $\mu$ l per-filter; BD Biosciences, Franklin Lakes, NJ, USA). The cells were seeded in the upper chamber $\left(1 \times 10^{5}\right.$ cells/well) in serum-free DMEM, and DMEM containing $10 \%$ FBS was added to the lower chambers as a chemoattractant. Following a $24 \mathrm{~h}$ incubation, the non-migratory cells in the upper chamber were removed using a cotton-tip applicator. The migrated cells on the lower surface were fixed with methanol and stained with hematoxylin. The number of migratory cells was determined by counting five random fields on each membrane.

miRNA extraction and detection by reverse transcription-quantitative polymerase chain reaction ( $R T-q P C R)$. Approximately $5 \times 10^{6}$ cells were collected following treatment with or without (control) propofol for $24 \mathrm{~h}$, and miRNAs were extracted using TRIzol $^{\circledR}$ reagent (Invitrogen Life Technologies), according to the manufacturer's instructions. miRNA-218 quantification was performed using the Bio-Rad iQ5 Multicolor Real-Time PCR (RT-PCR) Detection system (Bio-Rad Laboratories, Hercules, CA, USA) and the TaqMan ${ }^{\circledR}$ MicroRNA Reverse Transcription kit (Invitrogen Life Technologies). At the reverse transcription step, cDNA was synthesized from total RNA $(1 \mu \mathrm{g})$ using specific miRNA primers and reagents from the TaqMan ${ }^{\circledR}$ MicroRNA Reverse Transcription kit. At the PCR step, PCR products were amplified from cDNA using the TaqMan ${ }^{\circledR}$ MicroRNA Assay/TaqMan ${ }^{\circledR}$ Universal PCR Master mix. The following conditions were used for PCR: $40 \mathrm{Cycles}$ of $95^{\circ} \mathrm{C}$ for $10 \mathrm{~min} ; 95^{\circ} \mathrm{C}$ for $15 \mathrm{sec}$; and $60^{\circ} \mathrm{C}$ for $60 \mathrm{sec}$. U6 small nuclear RNA was used as an endogenous reference gene. The RT primers had the following sequences: 5'-GTCGTATCCAGTGCAGGGTCCGAGGTAT TCGCACTGGATACGACTCTTAGG-3' for miR-218 and 5'-TGGTGTCGTGGAGTCG-3' for U6. The PCR primers were designed as follows: Forward: 5'-TGCGGC GGCCCCACGCACCAG-3' and reverse: 5'-CCAGTGCAGGGT CCGAGGT-3' for miR-218; and forward: 5'- TGCGGGTGCT CGCTTCGGCAGC-3' and reverse 5'-CCAGTGCAGGGTC CGAGGT-3' for U6. The primers obtained from Qiagen. The cycle threshold $(\mathrm{Ct})$ was defined as the fractional cycle number at which fluorescence passed the fixed threshold, and the relative miR-218 expression levels were calculated using the $2^{-\Delta \Delta} \mathrm{Ct}$ method.

Western blot analysis. The U373 cells were homogenized using a dounce homogenizer (Corning, Shanghai, China) in ice-cold lysis buffer containing $10 \mathrm{mM}$ Tris ( $\mathrm{pH} 8.0$ ), $150 \mathrm{mM} \mathrm{NaCl}, 10 \%$ glycerol, $1 \%$ NP-40, 5 mM EDTA and a protease inhibitor cocktail (Sigma-Aldrich). The homogenates were then centrifuged at $13,200 \mathrm{x} \mathrm{g}$ for $20 \mathrm{~min}$ at $4^{\circ} \mathrm{C}$, and the total protein concentrations were quantified using a Bicinchoninic Acid Protein Assay kit (Beyotime Institute of Biotechnology, Haimen, China). Equal quantities of protein $(30 \mu \mathrm{g})$ were separated by SDS-PAGE using $12 \%$ gradient Tris/glycine gels. The proteins were then transferred to nitrocellulose membranes (EMD Millipore, Billerica, MA, USA). After blocking in 5\% non-fat dry milk for $1 \mathrm{~h}$, the blots were incubated with the affinity purified rabbit anti-MMP-2 (1:300) and $\beta$-actin $(1: 2,000)$ antibodies at $4^{\circ} \mathrm{C}$ overnight. The membranes were then washed and incubated for $2 \mathrm{~h}$ with peroxidase-labeled goat anti-rabbit immunoglobulin $\mathrm{G}$ (1:5,000, sc-2445; Santa Cruz Biotechnology, Inc.). The blots 
A

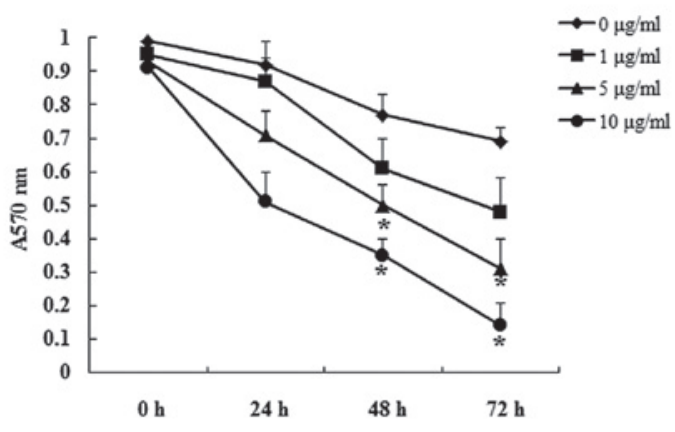

C

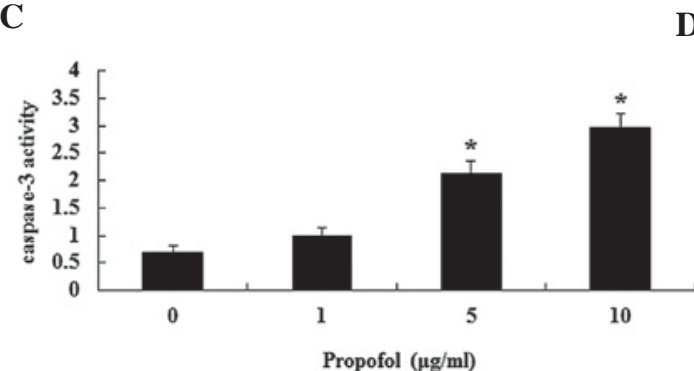

B

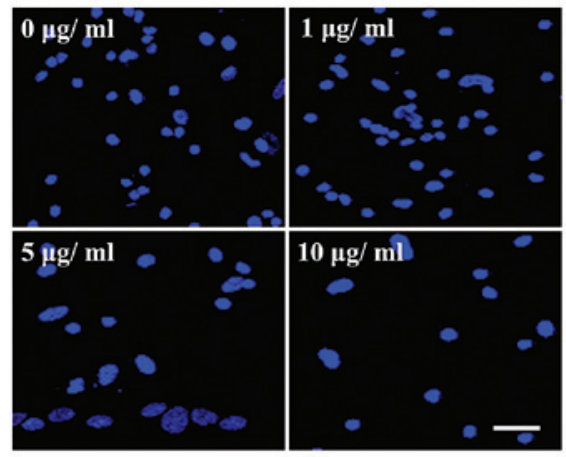

D

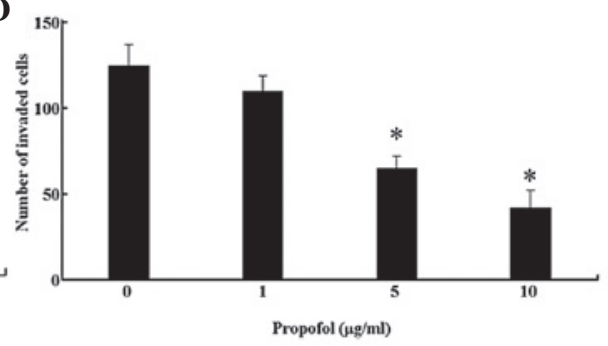

Figure 1. Effects of propofol on cell proliferation, apoptosis and invasion. (A) The MTT assay showed that the proliferation of U373 cells was markedly suppressed by propofol in a dose- and time-dependent manner. (B) Hoechst 33258 staining demonstrated promoted U373 cell apoptosis following propofol stimulation. (C) High caspase-3 activity was observed following propofol treatment. (D) A Matrigel invasion assay showed a significant decrease in the number of invaded cell numbers following propofol stimulation. "P<0.01, compared with the untreated control group.
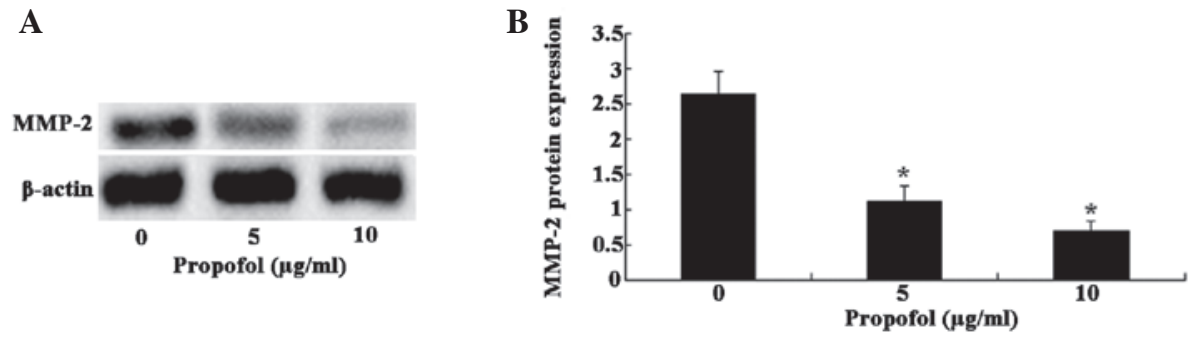

Figure 2. Western blot analysis showed that propofol treatment downregulated matrix metalloproteinase-2 (MMP-2) expression. (A) The protein levels of MMP-2 in U373 cells were markedly decreased following propofol treatment. (B) Statistical analysis of MMP-2 protein levels. "P<0.01, compared with the untreated control group.

were visualized using an Enhanced Chemiluminescence substrate (Applygen Technologies, Inc., Beijing, China) and exposed to X-ray film (Sigma-Aldrich). $\beta$-actin was used as an internal control for relative quantification. The grey value analysis of immunoreactive bands was performed using Quantity One software (Bio-Rad Laboratories).

Cell transfection procedures. The overexpression or knockdown of miR-218 was conducted by transfection of the U373 cells with either $100 \mathrm{nM}$ miR-218 precursor or anti-miR-218 or negative control (NC) RNA-oligonucleotides (Ambion Life Technologies, Carlsbad, CA, USA). The transfections were conducted using Lipofectamine $2000^{\circledR}$ (Invitrogen Life Technologies) in antibiotic-free medium, in 60-mm dishes, once the cells had reached $30-50 \%$ confluence. Following a $24 \mathrm{~h}$ incubation, the cells were treated with or without propofol.

Statistical analysis. All of the results represent the mean \pm SD. Statistical analyses were conducted using either an analysis of variance or Student's t-test. SPSS software v16 (SPSS Inc., Chicago, IL, USA) was used for statistical analysis. $\mathrm{P}<0.01$ was considered to indicate a statistically significant difference.

\section{Results}

Propofol suppresses cell proliferation and invasion, and facilitates apoptosis. The present study aimed to determine the effects of propofol on proliferation, apoptosis and invasion in the U373 glioma cell line. Following treatment with various concentrations of propofol, the proliferation of U373 cells was measured using the MTT method. The proliferation of U373 cells was markedly suppressed by propofol in a dose- and time-dependent manner (Fig. 1A). Treatment with propofol at 5 and $10 \mu \mathrm{g} / \mathrm{ml}$ significantly inhibited the proliferation of the cells at 48 and $72 \mathrm{~h}$. Furthermore, the rate of cell apoptosis was evaluated by Hoechst 33258 staining and caspase- 3 activity measurement. The U373 cells had an increased rate of apoptosis following treatment with propofol for $48 \mathrm{~h}$ (Fig. 1B and C). A Matrigel ${ }^{\mathrm{TM}}$ invasion assay 


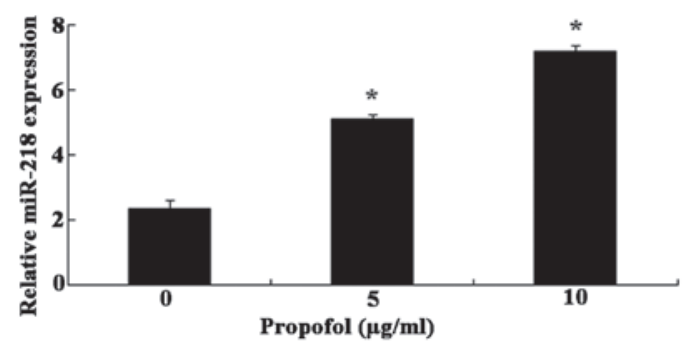

Figure 3. Propofol stimulates microRNA (miR)-218 expression in U373 human glioma cells. Propofol treatment increased the expression levels of miR-218 in a dose-dependent manner. "P<0.01, compared with the control untreated group.

A

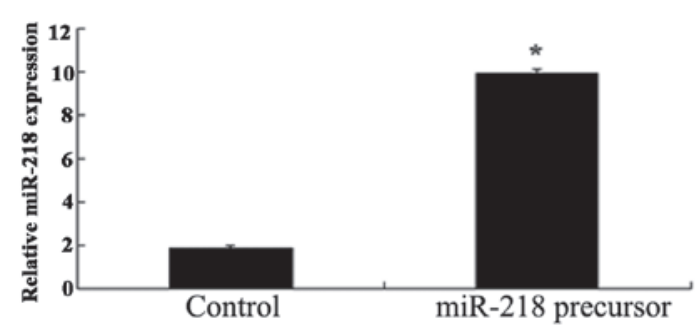

B

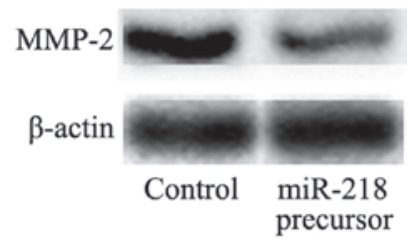

Figure 4. Overexpression of microRNA (miR)-218 can suppress matrix metalloproteinase (MMP)-2 expression. (A) Transfection of U373 human glioma cells with miR-218 precursor significantly elevated the expression levels of miR-218. (B) Western blot analysis indicated that transfection with miR-218 precursor decreased MMP-2 protein expression levels. ${ }^{*} \mathrm{P}<0.01$, compared with the control group.

also demonstrated that propofol significantly reduced cell invasion when the cells were treated with 5 and $10 \mu \mathrm{g} / \mathrm{ml}$ (Fig. 1D). These results indicate that propofol inhibits proliferation and invasion, and promotes apoptosis of U373 cells.

Inhibitory effects of propofol on MMP-2 protein expression levels. To confirm the inhibitory effects of propofol on MMP-2, the MMP-2 protein expression levels were examined in cells following treatment with propofol by western blot analysis (Fig. 2A). A marked reduction in MMP-2 protein expression levels were observed in the U373 cells treated with $5 \mu \mathrm{g} / \mathrm{ml}$ propofol, as compared with the control cells $(\mathrm{P}<0.01)$. In addition, propofol dose-dependently suppressed MMP-2 protein expression, with a $57.58 \%$ reduction at $5 \mu \mathrm{g} / \mathrm{ml}$ and a $73.86 \%$ decrease at $10 \mu \mathrm{g} / \mathrm{ml}$ (Fig. 2B).

Propofol stimulates miR-218 expression. Treatment with propofol dose-dependently augmented miR-218 expression in U373 cells (Fig. 3). Specifically, treatment with $5 \mu \mathrm{g} / \mathrm{ml}$ propofol enhanced the miR-218 expression in U373 cells 2.19 fold and $10 \mu \mathrm{g} / \mathrm{ml}$ propofol elevated the miR-218 expression in U373 cells 3.07 fold.

Overexpression of $m i R-218$ suppresses MMP-2 expression levels. The present study also investigated whether MMP-2 expression was manipulated by miR-218 in U373 cells. qPCR was performed to detect miR-218 expression levels, following transfection with miR-218 precursor. Notably, transfection of the U373 cells with miR-218 precursor significantly elevated the expression of miR-218 (Fig. 4A), and markedly decreased MMP-2 protein expression levels (Fig. 4B).

Effects of knockdown of miR-218 expression on cell proliferation, apoptosis and invasion. The role of miR-218 in the effects of propofol was further explored in U373 cells. Transfection of the cells with anti-miR-218 antibody was performed to knockdown miR-218 expression. The anti-miR-218 antibody significantly reduced miR-218 expression levels, suggesting the successful introduction of anti-miR-218 into the U373 cells (Fig. 5A). Furthermore, transfection with the anti-miR-218 antibody significantly reversed the inhibition of cell proliferation and invasion, and facilitation of apoptosis caused by propofol (Fig. 5B-E). In addition, the inhibitory effects of propofol on the protein expression levels of MMP-2 were markedly neutralized following transfection of the U373 cells with anti-miR-218 (Fig. 5F).

\section{Discussion}

Malignant glioma is the most common type of brain tumor worldwide and is often fatal (23). The present study investigated the effects of propofol on the behavior of human GBM cells and demonstrated that treatment with propofol suppressed the proliferation and invasion of U373 cells, and induced cell apoptosis. These results are concordant with numerous previous findings. Siddiqui et al (24) demonstrated that propofol could inhibit breast cancer cell growth, and Zhang et al $(21,25)$ showed that propofol effectively induced apoptosis and suppressed invasiveness of hepatocellular carcinoma cells. In addition, Miao et al (20) confirmed the inhibitory effects of propofol on the invasive activity of colon carcinoma cells. These results indicate that propofol may be a particularly suitable anesthetic for use in tumor surgery $(22,26,27)$.

The present study also analyzed the underlying mechanisms of the effects of propofol on U373 cell growth and invasion. The identification of miRNAs has substantially altered views in regards to gene regulation, and recent findings over the past few years have increased focus on miRNAs in cancer molecular 
A

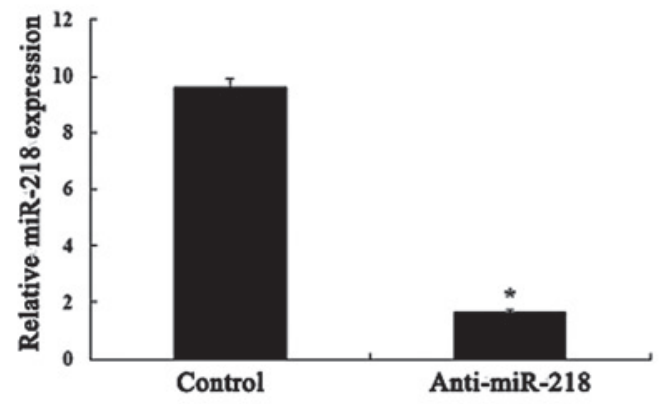

C

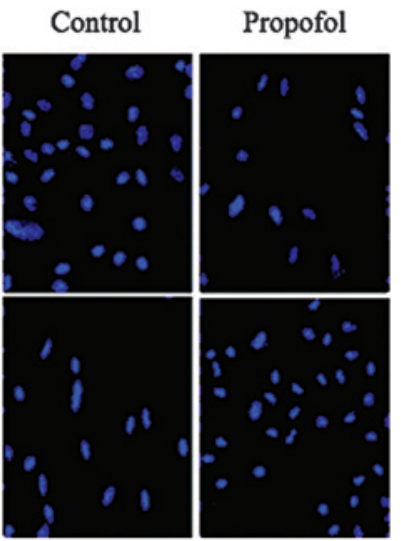

Propofol+Negative control Propofol+Anti-miR-218
B

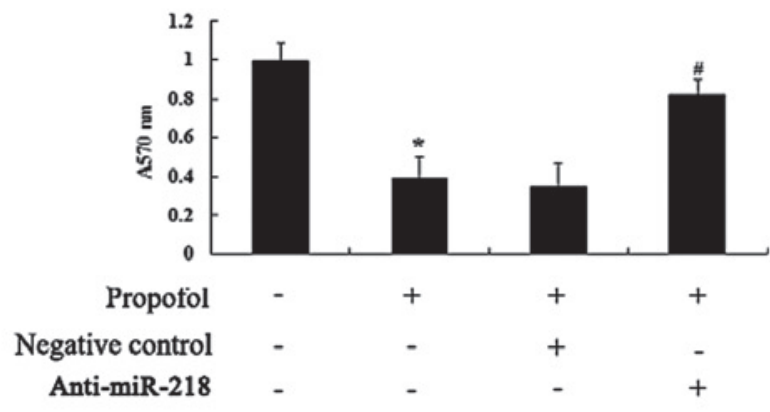

D

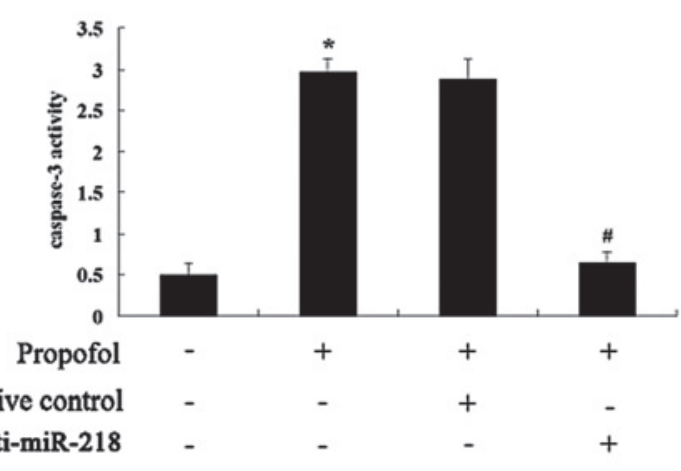

\section{$\mathbf{E}$}

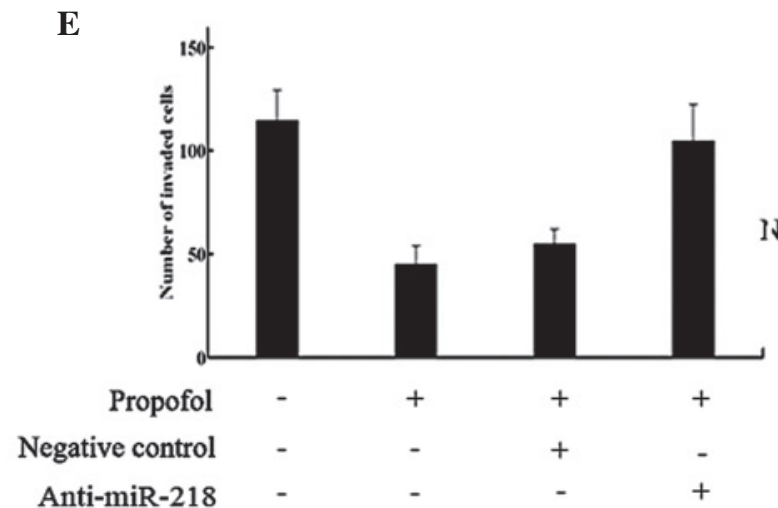

F

MMP-2

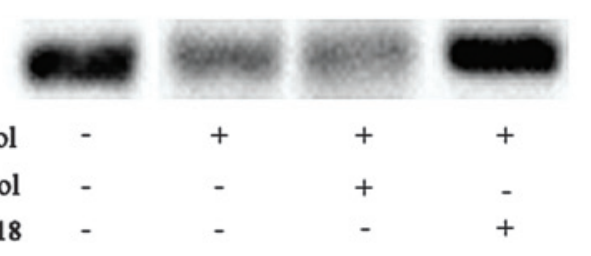

Figure 5. Anti-microRNA (miR)-218 can reverse the effect of propofol. (A) Reverse transcription-quantitative polymerase chain reaction showed decreased miR-218 expression after anti-miR-218 transfection. (B) An MTT assay indicated that anti-miR-218 enhanced U373 cell proliferation following treatment with $5 \mu \mathrm{g} / \mathrm{ml}$ propofol. (C) Hoechst 33258 staining and (D) caspase-3 activity measurement showed suppressed cell apoptosis after anti-miR-218 transfection in U373 cells pretreated with $5 \mu \mathrm{g} / \mathrm{ml}$ propofol. (E) Matrigel invasion assay showed increased invasion of U373 cells after anti-miR-218 transfection. (F) Western blot analysis indicated that anti-miR-218 significantly increased matrix metalloproteinase-2 (MMP-2) protein expression in U373 cells after propofol treatment. ${ }^{*} \mathrm{P}<0.01$, compared with the untreated control group; ${ }^{*} \mathrm{P}<0.01$, compared with propofol-treated group transfected with negative control.

biology. The anti-tumor functions of miR-218 have been demonstrated in osteosarcoma (13), gastrointestinal stromal tumor (28), gastric cancer (29), colon cancer (30), head and neck squamous cell carcinoma (31), cervical squamous cell carcinoma (32) and renal cell carcinoma (33). A previous study also identified miR-218 as a tumor-suppressor in glioma (34). The present study observed that treatment with propofol stimulated the expression of miR-218 in U373 cells. Furthermore, neutralizing miR-218 with anti-miR-218 antibody reversed the effects of propofol on U373 cells. These results indicate that propofol-induced miR-218 upregulation may contribute to the anti-proliferative and anti-invasive effects of propofol. Using TaqMan ${ }^{\circledR}$ low-density arrays and RT-PCR, Ishikawa et al (35) corroborated the changes to miRNA expression profiles following treatment with propofol in animal models. Furthermore, Zhang et al $(21,25)$ showed that treatment with propofol promoted apoptosis and suppressed adhesion of hepatocellular carcinoma cells, by upregulation of miR-199a. However, the underlying mechanisms regarding how propofol influences miRNA expression remain unclear, and require further clarification.

It is clear that miRNAs perform their functions through regulating target gene expression. Identifying the downstream 
genes of miR-218 may aid in explaining its roles in tumor initiation and development. MMP-2, which degrades gelatin and type IV collagen, is closely associated with the invasive activity of numerous human malignancies, including glioma $(36,37)$. Recently, Jin et al (13) verified the regulatory function of miR-218 on MMP-2 expression. The present study showed that treatment with propofol and transfection with miR-218 decreased MMP-2 protein expression levels, and transfection with anti-miR-218 reversed the inhibitory effects of propofol on MMP-2 expression. However, it is predicted that an average miRNA may have $>100$ targets (38). Therefore, it is probable that there are other molecules that are targeted by miR-218, which may be involved in miR-218-mediated effects of propofol on glioma cell behavior.

In conclusion, the present study demonstrated that treatment with propofol may suppress proliferation and invasion, and induce apoptosis of glioma cells, at least partly through upregulation of miR-218 expression. However, further studies are required, in order to validate its clinical relevance.

\section{References}

1. Vescovi AL, Galli R and Reynolds BA. Brain tumour stem cells. Nat Rev Cancer 6: 425-436, 2006.

2. Wen PY and Kesari S: Malignant gliomas in adults. N Engl J Med 359: 492-507, 2008.

3. Stupp R, Mason WP, van den Bent MJ, et al: Radiotherapy plus concomitant and adjuvant temozolomide for glioblastoma. N Engl J Med 352: 987-996, 2005.

4. Xia H, Qi Y, Ng SS, Chen X, Li D, Chen S, Ge R, Jiang S, Li G, Chen Y, et al: microRNA-146b inhibits glioma cell migration and invasion by targeting MMPs. Brain Res 1269: 158-165, 2009.

5. Nakada M, Nakada S, Demuth T, Tran NL, Hoelzinger DB and Berens ME: Molecular targets of glioma invasion. Cell Mol Life Sci 64: 458-478, 2007.

6. Egeblad M and Werb Z: New functions for the matrix metalloproteinases in cancer progression. Nat Rev Cancer 2: 161-174, 2002.

7. Badiga AV, Chetty C, Kesanakurti D, et al: MMP-2 siRNA inhibits radiation-enhanced invasiveness in glioma cells. PloS One 6: e20614, 2011.

8. Bartel DP: MicroRNAs: genomics, biogenesis, mechanism and function. Cell 116: 281-297, 2004.

9. Zhang B, Pan X, Cobb GP and Anderson TA: microRNAs as oncogenes and tumor suppressors. Dev Biol 302: 1-12, 2007.

10. Xiao B, Tan L, He B, Liu Z and Xu R: MiRNA-329 targeting E2F1 inhibits cell proliferation in glioma cells. J Transl Med 11: 172, 2013.

11. Hui W, Yuntao L, Lun L, et al: MicroRNA-195 inhibits the proliferation of human glioma cells by directly targeting cyclin D1 and cyclin E1. PloS One 8: e54932, 2013.

12. Zhang C, Ge S, Hu C, Yang N and Zhang J: MiRNA-218, a new regulator of HMGB1, suppresses cell migration and invasion in non-small cell lung cancer. Acta Biochim Biophys Sin (Shanghai) 45: 1055-1061, 2013.

13. Jin J, Cai L, Liu ZM and Zhou XS: miRNA-218 inhibits osteosarcoma cell migration and invasion by down-regulating of TIAM1, MMP2 and MMP9. Asian Pac J Cancer Prev 14: 3681-3684, 2013.

14. Prudnikova TY, Mostovich LA, Kashuba VI, Ernberg I, Zabarovsky ER and Grigorieva EV: miRNA-218 contributes to the regulation of D-glucuronyl C5-epimerase expression in normal and tumor breast tissues. Epigenetics 7: 1109-1114, 2012.

15. Xia H, Yan Y, Hu M, et al: MiR-218 sensitizes glioma cells to apoptosis and inhibits tumorigenicity by regulating ECOP-mediated suppression of NF-אB activity. Neuro Oncol 15: 413-422, 2013.

16. Zhang JM, Sun CY, Yu SZ, et al: Relationship between miR-218 and CDK6 expression and their biological impact on glioma cell proliferation and apoptosis. Zhonghua Bing Li Xue Za Zhi 40: 454-459, 2011.
17. Hertzog JH, Campbell JK, Dalton HJ and Hauser GJ: Propofol anesthesia for invasive procedures in ambulatory and hospitalized children: experience in the pediatric intensive care unit. Pediatrics 103: E30, 1999.

18. Altenburg JD, Harvey KA, McCray S, Xu Z and Siddiqui RA: A novel 2,6-diisopropylphenyl-docosahexaenoamide conjugate induces apoptosis in T cell acute lymphoblastic leukemia cell lines. Biochem Biophys Res Commun 411: 427-432, 2011.

19. Mammoto T, Mukai M, Mammoto A, et al: Intravenous anesthetic, propofol inhibits invasion of cancer cells. Cancer Lett 184: 165-170, 2002.

20. Miao Y, Zhang Y, Wan H, Chen L and Wang F: GABA-receptor agonist, propofol inhibits invasion of colon carcinoma cells. Biomed Pharmacother 64: 583-588, 2010.

21. Zhang J, Zhang D, Wu GQ, Feng ZY and Zhu SM: Propofol inhibits the adhesion of hepatocellular carcinoma cells by upregulating microRNA-199a and downregulating MMP-9 expression. Hepatobiliary \& Pancreatic Diseases International 12: 305-309, 2013.

22. Inada T, Kubo K and Shingu K: Possible link between cyclooxygenase-inhibiting and antitumor properties of propofol J Anesth 25: 569-575, 2011.

23. Parsons DW, Jones S, Zhang X, et al: An integrated genomic analysis of human glioblastoma multiforme. Science 321: 1807-1812, 2008.

24. Siddiqui RA, Zerouga M, Wu M, et al: Anticancer properties of propofol-docosahexaenoate and propofol-eicosapentaenoate on breast cancer cells. Breast Cancer Res 7: R645-R654, 2005.

25. Zhang J, Wu GQ,Zhang Y, Feng ZY and Zhu SM: Propofol induces apoptosis of hepatocellular carcinoma cells by upregulation of microRNA-199a expression. Cell Biol Int 37: 227-232, 2013.

26. Siddiqui RA, Zerouga M, Wu M, et al: Anticancer properties of propofol-docosahexaenoate and propofol-eicosapentaenoate on breast cancer cells. Breast Cancer Res 7: R645-R654, 2005.

27. Wu RS, Liu KC, Tang NY, et al: cDNA microarray analysis of the gene expression of murine leukemia RAW 264.7 cells after exposure to propofol. Environ Toxicol 28: 471-478, 2013.

28. Fan R, Zhong J, Zheng S, et al: MicroRNA-218 inhibits gastrointestinal stromal tumor cell and invasion by targeting KIT. Tumour Biol 35: 4209-4217, 2014.

29. Gao C, Zhang Z, Liu W, Xiao S, Gu W and Lu H: Reduced microRNA-218 expression is associated with high nuclear factor kappaB activation in gastric cancer. Cancer 116: 41-49, 2010.

30. He X, Dong Y, Wu CW, et al: MicroRNA-218 inhibits cell cycle progression and promotes apoptosis in colon cancer by downregulating BMI1 polycomb ring finger oncogene. Mol Med 18: 1491-1498, 2013.

31. Kinoshita T, Hanazawa T, Nohata N, et al: Tumor suppressive microRNA-218 inhibits cancer cell migration and invasion through targeting laminin-332 in head and neck squamous cell carcinoma. Oncotarget 3: 1386-1400, 2012.

32. Yamamoto N, Kinoshita T, Nohata N, et al: Tumor suppressive microRNA-218 inhibits cancer cell migration and invasion by targeting focal adhesion pathways in cervical squamous cell carcinoma. Int J Oncol 42: 1523-1532, 2013.

33. Yamasaki T, Seki N, Yoshino H, et al: MicroRNA-218 inhibits cell migration and invasion in renal cell carcinoma through targeting caveolin-2 involved in focal adhesion pathway. J Urol 190: 1059-1068, 2013.

34. Tu Y, Gao X, Li G, et al: MicroRNA-218 inhibits glioma invasion, migration, proliferation and cancer stem-like cell self-renewal by targeting the polycomb group gene Bmi1. Cancer Res 73: 6046-6055, 2013.

35. Ishikawa M, Tanaka S, Arai M, Genda Y and Sakamoto A: Differences in microRNA changes of healthy rat liver between sevoflurane and propofol anesthesia. Anesthesiology 117: $1245-1252,2012$

36. Rundhaug JE: Matrix metalloproteinases, angiogenesis and cancer: commentary re: A. C. Lockhart et al: Reduction of wound angiogenesis in patients treated with BMS-275291, a broad spectrum matrix metalloproteinase inhibitor. Clin Cancer Res 9: 551-554, 2003.

37. Deryugina EI, Bourdon MA, Luo GX, Reisfeld RA and Strongin A: Matrix metalloproteinase-2 activation modulates glioma cell migration. J Cell Sci 110: 2473-2482, 1997.

38. Brennecke J, Stark A, Russell RB and Cohen SM: Principles of microRNA-target recognition. PLoS Biol 3: e85, 2005. 